\title{
The Study of the Thermal Treatment on the Surface Microstructure and Electrical Conductivity of the Copper/Graphite Composites
}

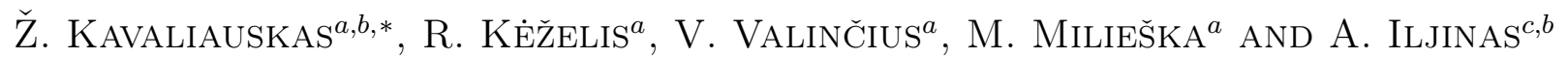 \\ ${ }^{a}$ Lithuanian Energy Institute, Breslaujos Str. 3, LT-44403 Kaunas, Lithuania \\ ${ }^{b}$ Kauno Kolegija/University of Applied Sciences, Pramones Str. 20, LT-50468, Kaunas, Lithuania \\ ${ }^{c}$ Kaunas University of Technology, Studentu Str. 50, LT-44249, Kaunas, Lithuania \\ (Received November 8, 2018; revised version September 9, 2019; in final form September 12, 2019)
}

\begin{abstract}
This research is aimed to analyze the effect of the migration mechanism of the copper layer deposited on the graphite surface using magnetron sputtering, with the influence on the microrelief structure and electrical properties of a copper-graphite composite. The research attempted to estimate the effect of copper migration on the microporosity structure, electrical conductivity, and specific surface area of a copper-graphite composite. The magnetron evaporation method was used to form $200 \mathrm{~nm}$ layers on graphite plate surface. The dimensions of irregularly shaped micro formations on the surface vary within the limits of $1-10 \mu \mathrm{m}$. By contrast, the measurements of Brunauer-Emmett-Teller specific surface area have demonstrated that the specific surface area of copper-graphite composites heated at $400{ }^{\circ} \mathrm{C}$ temperature is about 3 times smaller compared to the unheated ones, reaching about $6 \mathrm{~m}^{2} / \mathrm{g}$. Copper-graphite composites had the highest electric conductivity of $5 \mathrm{~S}$ when composites were heat treated at temperature of $200^{\circ} \mathrm{C}$.
\end{abstract}

DOI: 10.12693/APhysPolA.136.400

PACS/topics: plasma, copper, temperature, composites

\section{Introduction}

Graphite as a material is well known for its chemical inertia, mechanical strength, resistance to corrosion, and low cost. In addition, graphite has good self-lubricating properties. As a result, graphite composites are often used in the production of hard disk drives, moving devices in mechanical machinery, cutting tools, and elsewhere [1-3]. The insertion of additional materials (such as copper, titanium, aluminum) into carbon can significantly improve specific carbon properties: plasticity, electric conductivity, etc. The additional materials are inserted into carbon using different methods such as chemical technologies, alloy treatment, plasma spray technology, or magnetron sputtering technology [4-7]. The production of copper-graphite composites creates a big problem as due to high surface energy it is very difficult to provide wetting between copper and graphite surfaces. Such process requires high temperature environment (about $1000^{\circ} \mathrm{C}$ ). In order to solve that problem, the magnetron sputtering technology is applied, which causes the migration of copper atoms into graphite micropores. The process of magnetron evaporation is quite slow because vacuum is needed, and the speed of layer growth is low (not exceeding $10 \mathrm{~nm} / \mathrm{s}$ ). However, in certain cases the magnetron evaporation technology has a number of advantages over other coating formation methods as it

\footnotetext{
* corresponding author; e-mail: zydrunas. kavaliauskaslei@gmail.com
}

is possible to control the thickness of coating growth, change the composition of plasma forming gas, select the ambient pressure, etc. [8-11]. Those parameters strongly influence the physical properties of obtained nanolayers. In addition, the magnetron sputtering technology is a fairly reliable way to introduce copper atoms into the porous graphite structure. It is worth mentioning that the formation of thin copper layers on the graphite surface while applying thermal treatment combines two material transfer mechanisms: (i) the migration of copper atoms into the pores of the graphite surface; (ii) diffusion between copper and graphite layers. Despite multitude of researches related to the formation of different nanostructures using magnetron sputtering, there is still some uncertainty about the formation mechanisms of such thin structures as well as kinetic mechanisms of growing thin layers [12-15].

Copper as a metal is well known for its good electrical and thermal conductivity as well as excellent plasticity. As a result, it is widely used in the production of electrical appliances. However, copper also has a number of shortcomings, such as low mechanical hardness or weak resistance to the chemically active environment. In order to improve those properties, various materials are combined into composites such as copper-graphite. In addition to the magnetron sputtering technology, thermal treatment of up to $400^{\circ} \mathrm{C}$ is often used to obtain such composites. Graphite has porous structure, thus at the temperature of $400^{\circ} \mathrm{C}$ the copper atoms start to diffuse into the graphite surface layers and vice versa. Thermal treatment of a copper-graphite composite enables the migration of copper atoms into the micropores 
of graphite. The specific surface area of the treated composite is reduced, but the electrical properties are improved (increased electrical conductivity), and also the mechanical plasticity increases. Scientific literature provides significant amount of data about diffusion mechanisms of different metals and graphite. There is, however, a lack of information about the migration mechanisms of various materials (for example, metals) into pores $[1-3,5]$.

This research is aimed to analyze the effect of the migration mechanism of the copper layer deposited on graphite surface using magnetron sputtering, influence on the microrelief structure and electrical properties of a copper-graphite composite. The research attempted to estimate the effect of copper migration on the microporosity structure, electrical conductivity, and specific surface area of a copper-graphite composite.

\section{The course of the experiment}

The copper-graphite composites were formed using the magnetron sputtering method. The magnetron sputtering system was developed at the Department of Physics at Kaunas University of Technology. Thin copper coatings of up to $200 \mathrm{~nm}$ in thickness were formed on porous graphite plates. Thin copper layers on graphite plates were formed at $5 \times 10^{-3} \mathrm{~Pa}$ vacuum environment. Plasma was formed using argon gas, which was selected because it is inert and does not react with the environment. The pressure of working gas in the vacuum chamber was equal to $1 \mathrm{~Pa}$, while the distance between graphite plates and copper cathode was $65 \mathrm{~mm}$. The power of magnetron system during the deposition of thin coatings reached about $400 \mathrm{~W}$. Thin copper layers were growing at the speed of about $11 \mathrm{~nm} / \mathrm{min}$. In order to trigger the copper migration into graphite surface pores, as well as the process of diffusion, copper-graphite derivatives were thermally treated at the temperatures of $200^{\circ} \mathrm{C}, 300^{\circ} \mathrm{C}$, and $400^{\circ} \mathrm{C}$ at $5 \times 10^{-3} \mathrm{~Pa}$ vacuum level. The morphology of obtained coatings was analyzed using the scanning electron microscope (SEM) JEOL JSM-5600. The coating structure was analyzed by X-ray diffraction (XRD) (DRON-UM1 with standard Bragg-Brentano focusing geometry) in the $10-100^{\circ}$ range using the $\mathrm{Cu} K_{\alpha}(\lambda=0.154059 \mathrm{~nm})$ radiation. The specific electrical conductivity was measured using four probe method with the $100 \mu \mathrm{A}$ electric current flowing through the sample surface at $10 \mathrm{~V}$ voltage. The specific surface area of the coatings was measured by the Brunauer-Emmett-Teller (BET) method using the KELVIN 1042 sorptometer [16].

\section{Results and discussions}

Figure 1 presents the images of the surface microrelief of the copper-graphite composites obtained using a scanning electron microscope. Figure 1a shows the SEM
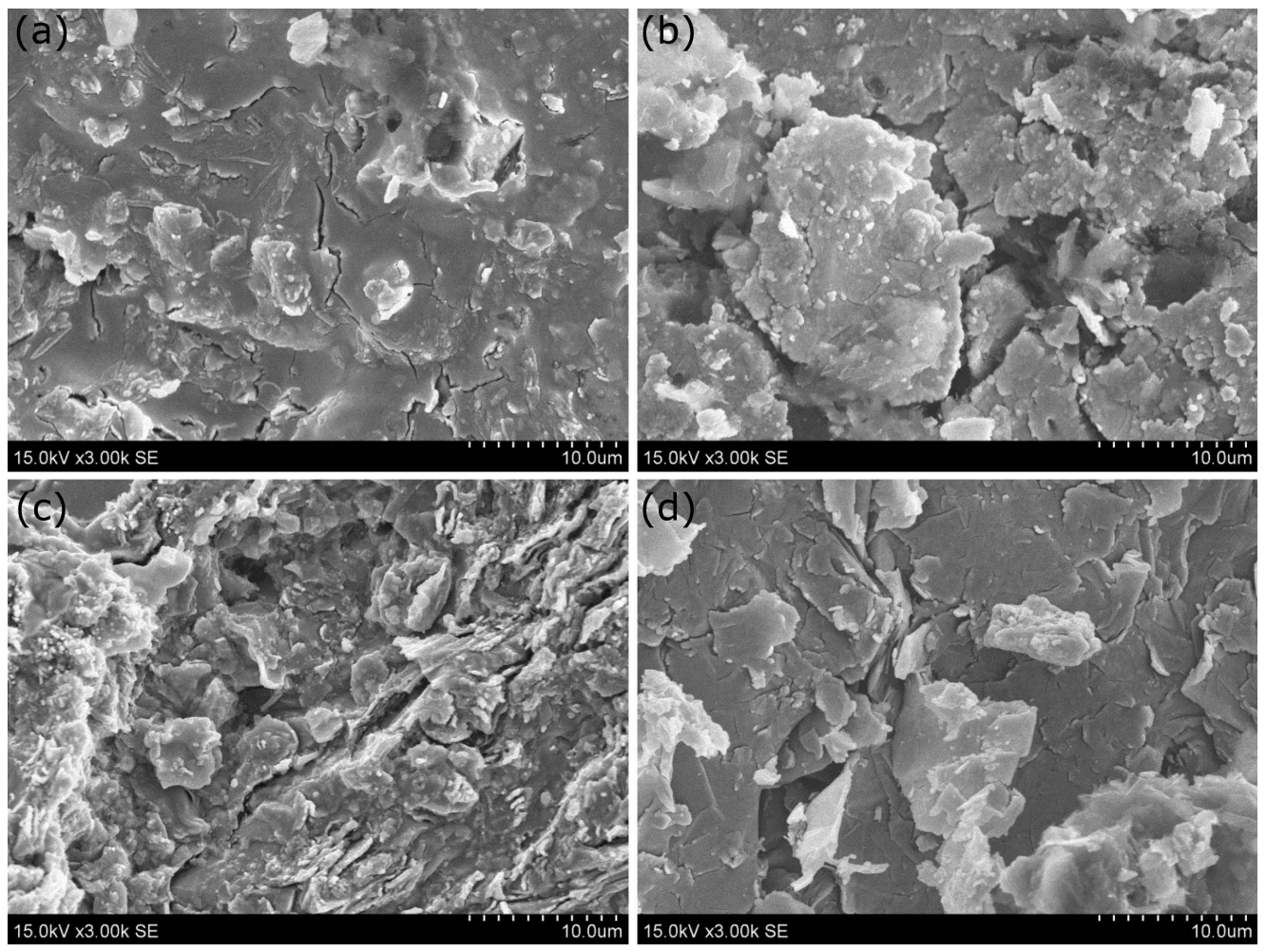

Fig. 1. The SEM images of the $200 \mathrm{~nm}$ copper layer on graphite: (a) copper-graphite composite before thermal treatment, (b) copper-graphite composite thermally treated at $200^{\circ} \mathrm{C}$, (c) copper-graphite composite thermally treated at $300^{\circ} \mathrm{C}$, (d) copper-graphite composite thermally treated at $400^{\circ} \mathrm{C}$. 
image of the copper-graphite surface before thermal treatment. It can be seen that the surface consists of microformations of irregular shape with the diameter of about $1-5 \mu \mathrm{m}$. Microcracks can be observed on the surface between microformations. In fact, they appeared during the formation of a thin copper layer.

Figures $1 \mathrm{~b}$ and $1 \mathrm{c}$ present the surface of samples, which were thermally treated at $200^{\circ} \mathrm{C}$ and $300^{\circ} \mathrm{C}$. The analysis of the SEM images reveals that in these case microcracks are significantly larger than those in Fig. 1a. These microcracks are directly influenced by the thermal treatment of copper-graphite as copper and graphite have different expansion coefficients. In addition, the surface has microformations with diameters up to $10 \mu \mathrm{m}$.

Figure 1d presents the surface of copper-graphite composite when it was treated at $400^{\circ} \mathrm{C}$ temperature. It can be seen that there are much less microcracks than in the demonstrated Fig. 1b and c. Such result could be explained by the fact that at $400{ }^{\circ} \mathrm{C}$ temperature copper atoms start migrating into graphite pores, eventually filling them [2]. Thus, that process eliminates part of microcracks, and the surface is smoother than in the two previous cases (Fig. 1b and c).

Figure 2 presents the XRD analysis of copper-graphite composite. According to the XRD analysis, the thermal treatment does not influence the copper-graphite structure noticeably. The X-ray spectra characteristic to copper and graphite are observed. The peaks typical for copper and graphite spectra at some angles match, and cover each other. It can be seen that graphite has crystal structure (most of carbon forms have amorphous structure). Analysis of copper spectrum reveal that the intensities of their peaks do not really change. Thus, it can be stated that the amount of copper deposited on the graphite surface is approximately equal in all cases.

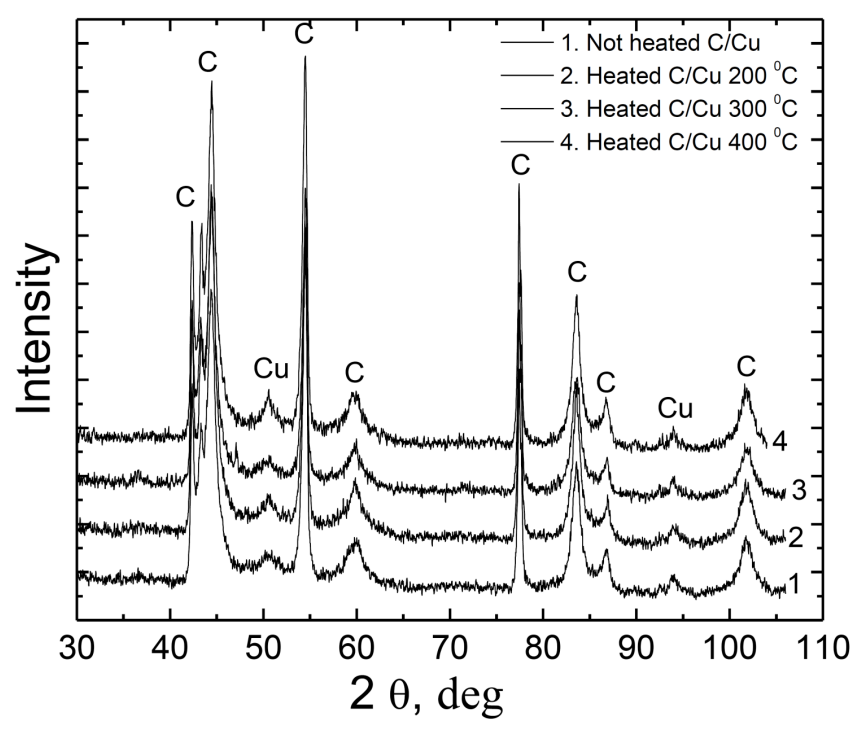

Fig. 2. The XRD analysis of copper-graphite composite at different thermal treatment temperatures.
Figure 3 presents the measurements of the specific surface area of the copper-graphite composite using BET methodology. According to the research results, when the thermal treatment temperature is $400^{\circ} \mathrm{C}$, the specific surface area is $6 \mathrm{~m}^{2} / \mathrm{g}$ and is about 3 times smaller than the surface area of the untreated composite. Such result can be explained by the fact that under thermal impact part of copper migrates into graphite pores and micro formations, thus filling them, and also reducing the specific surface area. Another factor affecting the change in the measured specific surface area could be the diffusion between copper and graphite layers which (according to the literature) starts at $400^{\circ} \mathrm{C}[1-4]$.

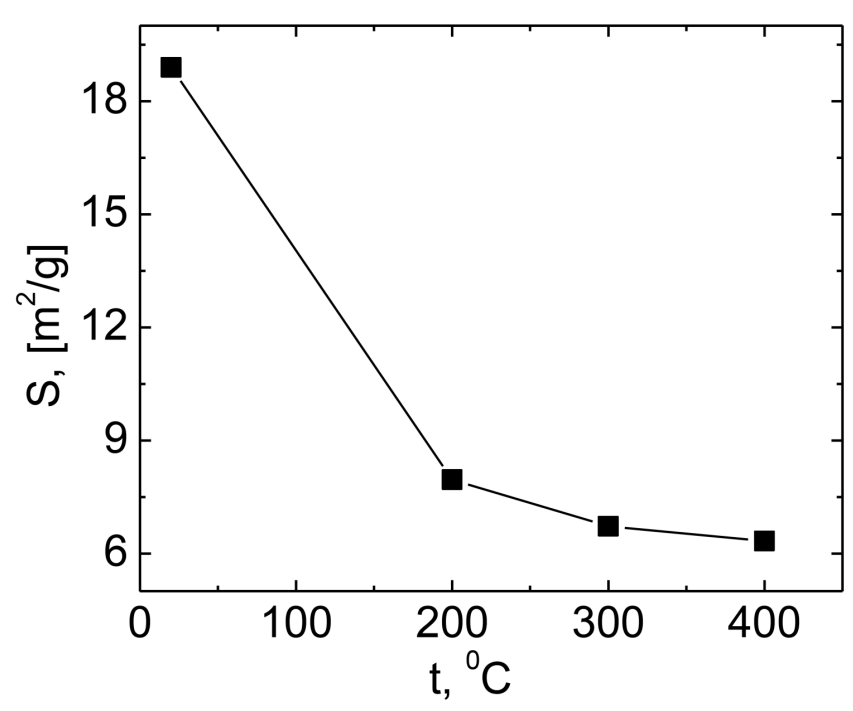

Fig. 3. Measurements of the specific surface area of copper-graphite composite after thermal treatment at different temperatures.

Figure 4 presents the analysis of the surface porosity of the copper-graphite composite, indicating the diameter of pores occupying respective surface area. According to the analysis, the surface is dominated by pores with diameters from 2 to $20 \mu \mathrm{m}$. Majority of pores have the diameter between 2 and $10 \mu \mathrm{m}$. It can be seen that the surface of untreated composite contains a lot more small diameter pores (forming specific surface area) than the surfaces of thermally treated copper-graphite composites. On the surface of untreated composite, pores of 2 $3 \mu \mathrm{m}$ diameter occupy from 12 to $16.5 \mathrm{~m}^{2} / \mathrm{g}$, while on the thermally treated surfaces - about $8 \mathrm{~m}^{2} / \mathrm{g}$. Those results correlate well with the measurements of the specific surface area presented in Fig. 3, because as the larger area is taken by the smallest pores, the greater is the specific surface area of respective material. By contrast, there are much less pores of $2-3 \mu \mathrm{m}$ diameter on the surfaces of thermally treated samples compared to thermally untreated ones, as during the thermal treatment copper migrates from the surface into graphite pores and fills them completely. 


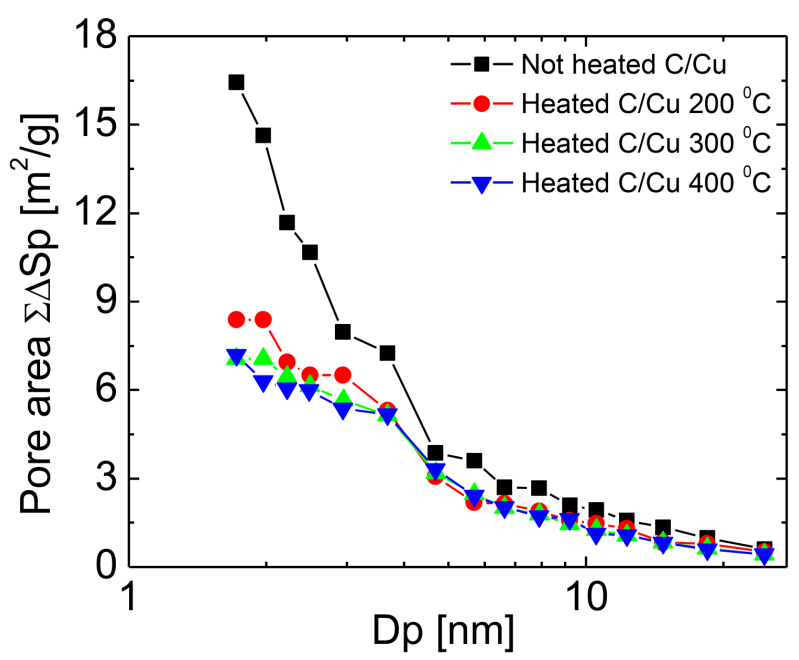

Fig. 4. The distribution of pores on the surface of copper-graphite composite according to their diameter after thermal treatment at different temperatures.

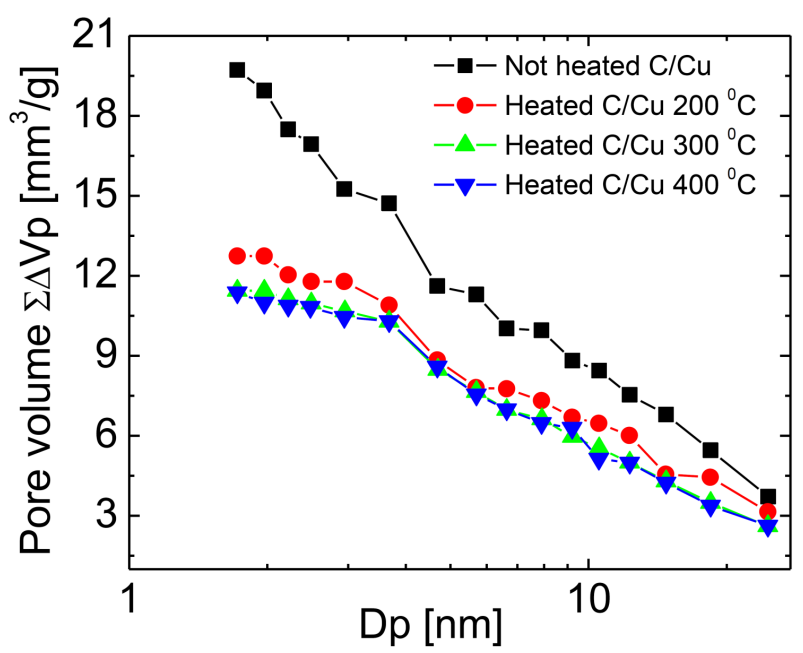

Fig. 5. The distribution of pores volume on the surface of copper-graphite composite according to diameter after thermal treatment at different temperatures.

Figure 5 presents the surface porosity analysis of copper-graphite composite showing the diameter of pores occupying respective surface volume. According to the analysis, small diameter $(2-5 \mu \mathrm{m})$ pores occupy the largest total volume (15 to $20 \mathrm{~mm}^{3} / \mathrm{g}$ ) on the surface of thermally untreated copper-graphite composite.

The explanation of the above results in the case of thermally treated composites is that the copper from the surface migrates into the surface of the graphite pores and fills them.

Figure 6 presents the electric conductivity measurements of copper-graphite composites of different thermal treatment temperatures. The measurement registers the lowest electric conductivity for thermally untreated composites reaching about $2 \mathrm{~S}$. After the thermal treatment

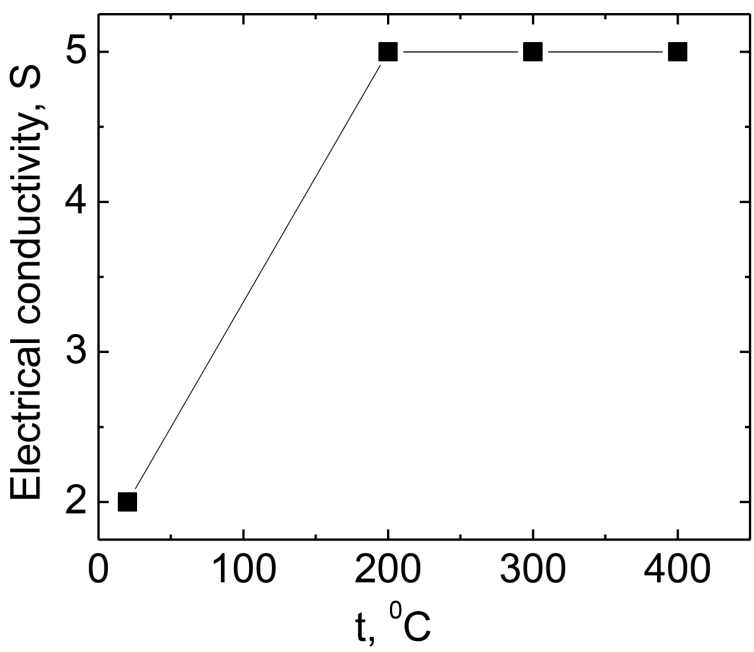

Fig. 6. The dependence of the electric conductivity of copper-graphite composite for samples after different thermal treatment.

of copper-graphite composites at $200{ }^{\circ} \mathrm{C}$ or higher temperature, the electric conductivity increases up to $5 \mathrm{~S}$. Further increase of the temperature does not alter the electric conductivity, which remains constant.

The increase in the electric conductivity of thermally treated composites is determined by the mechanisms of copper migration and diffusion into graphite surface pores and layers [1-2]. The copper in the surface layers of a composite has lower specific electric resistance than graphite. As a result, the copper-graphite composite itself has a larger number of particles (free ions and electrons) participating in the transfer of electric current and increasing the volume density of electric current.

\section{Conclusion}

The magnetron sputtering method was used to form $200 \mathrm{~nm}$ copper layers on the graphite plate surface. The surface analysis of SEM have revealed that microcracks develop on the surface of copper-graphite composites during the formation of a copper layer due to different thermal expansion coefficients of copper and graphite. The dimensions of irregularly shaped microformations on the surface varies within the limits of $1-10 \mu \mathrm{m}$. The analysis of X-ray diffraction have revealed that the thermal treatment of a copper-graphite composite does not have a noticeable impact on the crystalline structure. By contrast, the measurements of BET specific surface area have demonstrated that the specific surface of copper-graphite composites heated at $400{ }^{\circ} \mathrm{C}$ temperature is about 3 times smaller compared to the unheated ones, reaching about $6 \mathrm{~m}^{2} / \mathrm{g}$. The porosity analysis has disclosed that the largest total volume and area are occupied by pores of 2-3 $\mu \mathrm{m}$ diameter existing on the surface of unheated copper-graphite composite. Meanwhile, part of small diameter pores in thermally treated composites are filled 
due to copper atoms migration and diffusion. Coppergraphite composites had the highest electric conductivity of $5 \mathrm{~S}$ when composites were heat treated at $200^{\circ} \mathrm{C}$ temperature. The increase of the heating temperature up to $30{ }^{\circ} \mathrm{C}$ or more does not change the electric conductivity, which remains constant.

\section{References}

[1] W. Wang, L. Ji, H. Li, H. Zhou, J. Chen, J. Alloys Comp. 722, 242 (2017).

[2] I.L. Velicu, V. Tiron, B.G. Rusu, G. Popa, Surf. Coat. Technol. 327, 192 (2017).

[3] J.P. Yen, C.C. Chang, Y.R. Lin, S.T. Shen, J.L. Hong, J. Alloys Comp. 598, 184 (2014).

[4] D. Fuks, K.C. Mundim, L.A.C. Malbouisson, A. Berner, S. Dorfman, D.E. Ellis, J. Mol. Struct. (Theochem) 539, 199 (2001).

[5] G.A. Bleykher, A.O. Borduleva, A.V. Yuryeva, V.P. Krivobokova, J. Lančok, J. Bulír, J. Drahokoupil, L. Klimša, J. Kopeček, L. Fekete, R. Ctvrtlìk, J. Tomaštik, Surf. Coat. Technol. 324, 111 (2017).

[6] B. Giroire, M.A. Ahmad, G. Aubert, L. Teule-Gay, D. Michau, J.J. Watkins, C. Aymonier, A. PoulonQuintina, Thin Solid Films 643, 53 (2017).
[7] A.A. Solovyev, V.A. Semenov, V.O. Oskirko, K.V. Oskomov, A.N. Zakharov, S.V. Rabotkin, Thin Solid Films 631, 72 (2017).

[8] J.D. Lim, P.M. Lee, D. Rhee, K.C. Leong, Z. Chen, Appl. Surf. Sci. 355, 509 (2015).

[9] B.T. Quinton, K.D. Leedy, J.W. Lawson, B. Tsao, J.D. Scofield, J.N. Merrett, Q. Zhang, K. Yost, S.M. Mukhopadhyay, Carbon 87, 175 (2015).

[10] H. Fujimoto, T. Miyayama, N. Sanada, C. Adachi, Org. Electron. 14, 2994 (2013).

[11] J. García-Céspedes, S. Thomasson, K.B.K. Teo, I.A. Kinloch, W.I. Milne, E. Pascual, E. Bertran, Carbon 47, 613 (2009).

[12] C.L. Chu, H.C. Lu, C.Y. Lo, C.Y. Lai, Y.H. Wang, Physica B Condens. Matter 404, 4831 (2009).

[13] A. Iljinas, V. Stankus, Thin Solid Films 601, 106 (2016).

[14] M. Černauskas, L. Marcinauskas, R. Zabels, Thin Solid Films 615, 195 (2016).

[15] G. Laukaitis, J. Dudonis, D. Milcius, Vacuum 81, 1288 (2007).

[16] M. Naderi, "Surface Area: Brunauer-Emmett-Teller (BET)", in: Progress in Filtration and Separation, 2015, Ch. 14, p. 585. 